\title{
Correction to: Myoclonic status epilepticus and cerebellar hypoplasia associated with a novel variant in the GRIA3 gene
}

\author{
Berardo Rinaldi ${ }^{1}$ Y Yu-Han Ge $\mathrm{G}^{2,3}$ - Elena Freri ${ }^{4}$ - Arianna Tucci ${ }^{5}$. Tiziana Granata ${ }^{4}$ Margherita Estienne ${ }^{4}$. \\ Jia-Hui Sun ${ }^{2,3} \cdot$ Bénédicte Gérard $^{6} \cdot$ Allan Bayat $^{7,8} \cdot$ Stephanie Efthymiou ${ }^{9} \cdot$ Cristina Gervasini $^{10} \cdot$ Yun Stone Shi $^{2,3}$. \\ Henry Houlden ${ }^{9} \cdot$ Paola Marchisio $^{1} \cdot$ Donatella Milani $^{1}$
}

Published online: 27 November 2021

(c) The Author(s) 20212021

\section{Correction to: Neurogenetics https://doi.org/10.1007/s10048-021-00666-1}

In the original published article, the name of the seventh author has been misspelled.

"Jia-Hun Sun" should be "Jia-Hui Sun".

This is being corrected in this publication.

Open Access This article is licensed under a Creative Commons Attribution 4.0 International License, which permits use, sharing, adaptation, distribution and reproduction in any medium or format, as long as you give appropriate credit to the original author(s) and the source, provide a link to the Creative Commons licence, and indicate if changes were made. The images or other third party material in this article are included in the article's Creative Commons licence, unless indicated otherwise in a credit line to the material. If material is not included in the article's Creative Commons licence and your intended use is not permitted by statutory regulation or exceeds the permitted use, you will need to obtain permission directly from the copyright holder. To view a copy of this licence, visit http://creativecommons.org/licenses/by/4.0/.

Publisher's note Springer Nature remains neutral with regard to jurisdictional claims in published maps and institutional affiliations.
The original article can be found online at https://doi.org/10.1007/ s10048-021-00666-1.

\section{Arianna Tucci}

a.tucci@qmul.ac.uk

Yun Stone Shi

yunshi@nju.edu.cn

1 Fondazione IRCCS Ca' Granda Ospedale Maggiore Policlinico, Milan, Italy

2 Ministry of Education Key Laboratory of Model Animal for Disease Study, Department of Neurology, Drum Tower Hospital, Medical School, Nanjing University, Nanjing, China

3 State Key Laboratory of Pharmaceutical Biotechnology, Model Animal Research Center, Institute for Brain Sciences, Chemistry and Biomedicine Innovation Center, Nanjing University, Nanjing, China

4 Department of Pediatric Neuroscience, Fondazione IRCCS Istituto Neurologico C. Besta, Milan, Italy
5 Clinical Pharmacology, William Harvey Research Institute, School of Medicine and Dentistry, Queen Mary University of London, London EC1M 6BQ, UK

6 Laboratoires de diagnostic génétique, Institut Medical d'Alsace, Hôpitaux Universitaire de Strasbourg, Strasbourg, France

7 Department for Genetics and Personalized Medicine, Danish Epilepsy Centre, Dianalund, Denmark

8 Institute for Regional Health Services Research, University of Southern Denmark, Odense, Denmark

9 Department of Neuromuscular disorders, UCL Queen Square Institute of Neurology, London, UK

10 Medical Genetics, Department of Health Sciences, Università degli Studi di Milano, Milan, Italy 